\title{
Narrativas de professores sobre sua formação e atuação em classes hospitalares
}

DOI 10.26512/Ic.v24i0.18967

\author{
Cristiane Nobre Nunes \\ Universidade Cidade de São Paulo
}

Ecleide Cunico Furlanetto

Universidade Cidade de São Paulo

\section{Resumo}

No Brasil, as classes hospitalares são reconhecidas por lei como um direito das crianças e adolescentes hospitalizados. No entanto, o país conta com poucos hospitais que desenvolvem esse atendimento e, na maioria das vezes, prestado por profissionais que não possuem formação especifíca para esse fim. $O$ artigo analisa as narrativas de sete professoras que atuam em classes hospitalares de um hospital da cidade de São Paulo, que presta atendimento a pessoas com tumores malignos. O foco da análise é ampliar a compreensão dos processos formativos desses professores e de oferecer subsídios para a formação de docentes que atuam nas classes hospitalares.

Palavras-chave: Pedagogia hospitalar. Formação de professores de classes hospitalares. Pesquisa com narrativas. 


\section{What teachers have to count on his training and action in hospital classroom}

\section{Abstract}

In Brazil, the hospital classrooms are recognized by law as children and adolescent's rights, however the country has few hospitals that develop this care and, most of the time, provided by professionals who do not have specific training. The article analyzes the narratives of seven teachers who work in a school located in a reference hospital, that provides care to people with malignant tumors, in the city of São Paulo. It aims to broaden the understanding of their formative processes and thus grants subsidies for the training of teachers who work in the hospital classrooms.

Keywords: Hospital pedagogy. Training of teachers of hospital classrooms. Research with narratives.

\section{Qué os profesores tienen a contar sobre su formación y actuación en clases hospitales}

\section{Resumen}

En Brasil, las clases hospitalarias son reconocidas por ley como un derecho de los niños y adolescentes hospitalizados. Sin embargo, el país cuenta con pocos hospitales que desarrollan este tipo de atención. En la mayoría de las veces, elle es prestada por profesionales que no poseen formación específica para ese fin. El artículo analiza las narrativas de siete profesoras que actúan en una escuela ubicada en un hospital de la ciudad de São Paulo que presta atención a personas con tumores malignos. El enfoque del análisis es ampliar la comprensión de los procesos formativos de estos profesores y de ofrecer subsidios para la formación de docentes que actúan en las clases hospitalarias.

Palabras clave: Pedagogía hospitalaria. Formación de profesores de clases hospitalarias. Investigación con narrativas. 


\section{Ce que les enseignants doivent compter sur sa formation et ses actions dans les classes hospitalières}

\section{Résumé}

Au Brésil, les classes hospitalières sont reconnues par la loi comme un droit des enfants et des adolescents hospitalisés. Cependant il y a peu d'hôpitaux au Brésil qui développent ce type d'attention à l'enfance, la plupart du temps, les enseignants n'ont pas de formation spécifique à cet effet. L'article analyse des récits de sept enseignants qui travaillent dans une classe hospitalière d'un hôpital de référence à la ville de São Paulo, qui accueille des malades atteints des tumeurs malignes. L'analyse focalise sur la compréhension des processus de formation des enseignants dans le but de contribuer pour la formation des enseignants qui travaillent dans des classes hospitalières.

Mots-clés: Pédagogie hospitalière. Formation des enseignants des classes hospitalières. Recherche avec des récits. 
Que tempo é este que se instaura então, o tempo da doença. Será um tempo da impotência, um tempo morto? Será o tempo de uma experiência que, tocando o corpo, nos faz experimentá-lo de outra forma, em sua fragilidade e seus limites, e nos ensina nossa finitude?

Christine Delory-Momberger (2016)

\section{A contextualização do tema}

Que tempo é este que retira as crianças do convívio com suas famílias que as afasta da escola que as insere em outro espaço, o do hospital? Para amenizar essa interrupção na vida de quem adoece, gravemente, em tenra idade surgiu como possibilidade de atenuação: a classe hospitalar que atualmente é considerada um direito adquirido pelas crianças e adolescentes que estão internados e impossibilitados de frequentar a escola regular. Alguns hospitais, cada vez mais, cientes de que devem prestar atendimento humanizado a essa população estão aderindo, mesmo com algumas dificuldades, a essa proposta, o que deve ocorrer levando em conta, não somente suas necessidades físicas, mas sociais e psicológicas. Embora esse direito seja assegurado legalmente, ainda é necessário percorrer um longo caminho para que o atendimento em classes hospitalares seja uma realidade nos hospitais brasileiros.

A classe hospitalar surge da necessidade de fazer o acompanhamento pedagógico de crianças e adolescentes com problemas de saúde e que estão temporariamente impedidos de frequentar a escola regular. Ela se apresenta como uma oportunidade das crianças e adolescentes participar de rotinas diferentes daquelas concernentes à doença, de forma preservar alguns vínculos com sua escola de origem e, consequentemente, com sua vida fora do hospital.

Cabe destacar que a representação, comumente tida de uma sala de aula: alunos de idades próximas, uniformizados, sentados em fila diante de um professor e de uma lousa, não se adéqua, propriamente, à realidade pedagógica vivida no hospital. Nesse local, o trabalho educativo nem sempre ocorre num espaço destinado a esse fim. Por não ter espaço físico próprio, ou em função do aluno estar impossibilitado de se locomover, ele acontece nos leitos, nas enfermarias, nas UTIs ou em espaços que possam ser utilizados para reunir grupos multietários. Cabe salientar que essas ações, apesar de se afastarem da lógica que estrutura a escola regular, não devem ser fruto de improvisações, mas, sim de uma outra lógica que inclui as singularidades dos alunos no atendimento prestado. Para atuar nessas condições, é necessário que profissionais recebam uma formação que os habilite a executar seu trabalho de uma forma humana e eficaz. 
A pedagogia hospitalar tem sido alvo de discussão em alguns trabalhos, como nos de Fontes (2005) e Schilke (2008) que recuperam sua história e a definem como um novo campo de estudos. No que se refere ao preparo do profissional habilitado para o atendimento educacional de crianças e adolescentes hospitalizados, é importante salientar que, apesar de haver trabalhos que abordam essa temática, como os de Schilke (2008) e de Silva (2010), é necessário realizar mais estudos que subsidiem os processos formativos de quem atua no hospital. Nessa direção, autores como Mazer e Tinós (2003) e Paula, E. M.A.T. e Matos, E. (2007) reafirmam essa percepção.

Com intuito de orientar o trabalho de profissionais de educação para trabalhar na classe hospitalar, foi publicado um documento do Governo Federal, denominado: Classe hospitalar e atendimento pedagógico domiciliar: estratégias e orientações (Ministério da Educação. Secretaria de Educação Especial. [MEC/SEESP], 2002), o referido documento buscou disponibilizar para os educadores que atuam nos hospitais, fundamentos para o atendimento pedagógico de pacientes acometidos por doenças graves que impedem a frequência às escolas regulares.

O documento faz menção à estrutura organizacional da classe hospitalar, salientando a importância de existir a presença de um professor coordenador que possua um repertório que o habilite atuar como docente em ambientes hospitalares e, para isso, ele deve conhecer a dinâmica dos centros hospitalares, as patologias de seus alunos e as possíveis consequências emocionais delas decorrentes, bem como as terapêuticas utilizadas para abordá-las o que torna possível ao professor, levar conta o quadro de saúde de seus alunos, ao programar as atividades pedagógicas, adaptando e flexibilizando as sequências didáticas ao estado do paciente.

Apesar das imensas dificuldades encontradas, a implantação das classes hospitalares está ocorrendo e para que ela aconteça a contento, é imprescindível que haja, além da expansão dos trabalhos educacionais, a realização de novas pesquisas que ofereçam suporte para o desenvolvimento de atividades educativas nos hospitais.

Caminhando nessa direção, foi desenvolvido um estudo cujo objetivo foi: investigar, por meio de narrativas, as trajetórias de formação de professores que atuam em uma escola situada em um hospital da Cidade de São Paulo que atende, unicamente, pacientes com tumores malignos. A pesquisa, por sua vez, deu origem a esse artigo que dialoga, mais uma vez com os dados, buscando pôr em evidência temas relevantes abordados pelos participantes da pesquisa.

\section{Como a pesquisa foi delineada?}

A pesquisa pautou-se no enfoque narrativo, partiu-se do pressuposto que as narrativas se configuram como modos de explicitar o que nos acontece e como acontece e as marcas deixadas acontecimentos em nossa existência. Segundo Bolívar (2002), a narrativa não é apenas uma metodologia, mas uma maneira de construir a realidade, na qual a subjetividade é considerada condição necessária para o conhecimento social, 
ela não somente expressa as experiências individuais, mas expressa a construção social da realidade. Por sua vez, o enfoque narrativo desvela um eu capaz de dialogar e cuja subjetividade se constitui intersubjetivamente. Nessa perspectiva, o jogo de subjetividades em um processo dialógico se constitui em um modo privilegiado de construir conhecimento.

Para Delory-Momberger (2016) falar sobre a construção da experiência é um modo de expressar a maneira pela qual cada um se apropria do vivido e pela qual se transforma precisamente em experiência. Muito do que se vive se instala à margem da consciência pode ser contatado por meio da narrativa e dessa forma, se tornar experiência constitutiva do eu. Por sua vez, Souza (2014) salienta que as narrativas coletadas em pesquisa ou em processos formativos se centram nas trajetórias, percursos e experiências e revelam o ato de lembrar, narrar e escrever sobre si. No contexto da pesquisa, essas narrativas se configuram como corpus de análise e por meio da análise compreensiva-interpretativa são acessados aspectos fundamentais das experiências dos sujeitos que permitem uma compreensão aprofundada da realidade social, nas quais estão inseridas.

Para a produção de uma narrativa coletiva dos professores foi utilizada a técnica do grupo focal que permite, segundo Gatti, (2005), compreender processos de construção da realidade por determinados grupos sociais que partilham alguns traços em comum, pertinentes ao problema estudado.

Participaram da pesquisa sete professoras que atuam na Escola Especializada Schwester Heine, fundada em 1987 por Carmem Prudente e Maria Genoveva Vello com o intuito de atender pacientes da Oncologia Pediátrica do Hospital A. C. Camargo, localizado na cidade de São Paulo. A escola vem se constituindo como um espaço pedagógico e cultural cujo o objetivo é evitar que crianças e adolescentes percam seus vínculos com a escola em razão do tratamento de saúde e possam se reintegrar ao convívio escolar após o término da internação. Atualmente, ela é considerada uma referência nacional em Pedagogia Hospitalar.

Quantos às professoras, é importante destacar que todas estavam vinculadas a redes públicas de ensino e foram cedidas para atuar nas classes hospitalares da escola. As participantes da pesquisa possuíam curso superior, sendo que três eram pedagogas, uma fonoaudióloga, uma psicóloga, uma licenciada em letras e outra em biologia. Todas haviam feito cursos de pós-graduação, algumas em psicopedagogia, outras em educação especial e duas tinham mestrado. Todas, também, tinham participado do curso de extensão em pedagogia hospitalar, oferecido pela Escola Especializada Schwester Heine, condição para atuar na escola. 


\section{O que as professoras têm para contar?}

As narrativas das professoras, por terem sido produzidas mediante grupo focal foram se entrelaçando e se constituindo em uma narrativa coletiva, o que levou as pesquisadoras a não nomear as professoras, individualmente, no presente artigo, pois se considerou que o foco não era destacar o que cada uma pensava, mas sim elementos da narrativa elaborada coletivamente, mediante um processo intersubjetivo. A análise dessa narrativa coletiva se deu por meio de sucessivas aproximações, com intuito de se apreender os principais temas emergentes e resultou na elaboração de mais uma narrativa que se constituiu neste artigo. Nessa perspectiva, esse artigo se configura como uma narrativa que entrelaça diferentes olhares sobre os temas abordados: os das professoras, os de alguns autores que estudam a temática em questão e por fim o das pesquisadoras.

\section{O exercício da docência nas classes hospitalares}

Inicialmente, as participantes da pesquisa sentiram necessidade de falar a respeito do exercício da docência, em classes hospitalares, trabalho que para elas ganha conotações específicas, pois os alunos estão acometidos de doenças graves que impõem uma nova realidade a eles. Como afirmam, Passeggi, Rocha e De Conti (2016): a doença e a consequente internação constituem para as crianças um momento de virada autobiográfica, uma ruptura que transforma suas vidas. A partir desse acontecimento, não se encontram mais em casa, estão afastadas de seus familiares, não podem mais frequentar a escola, nem passear e nem brincar com os amigos. Delory-Momberger (2016, p.26) nos alerta:

A doença pede atenção, cuidado. Ela desvia o curso dos dias e das noites, dobra-o segundo sua exigência, modula-o na imprevisibilidade de sua progressão, nutre-se do sentimento de vida para não ceder o lugar àquele da morte, embora este se torne presente.

Conviver com ela nos hospitais, fustigando as crianças e jovens, exige dos professores que atuam nas classes hospitalares algo mais e elas falam disso:

O perfil do professor é totalmente diferenciado, a nossa fala é diferente, tem que ter curiosidade, vontade, e ter superação, porque uma única criança pode ter várias patologias: ser cega, surda, deficiente física ou com distúrbio psicomotor. (Professoras)

O depoimento dessa professora mostra que exercer a docência nessas condições, não é fácil, o professor é, constantemente, deslocado e remexido, o que o faz rever suas 
práticas para se adequarem às necessidades educativas peculiares, decorrentes dos quadros de saúde de seus alunos. Para as participantes, o professor exerce a função de mediador entre o aluno e a doença, pois os alunos querem saber mais sobre seu estado de saúde, sobre os tratamentos a que são submetidos, questões essas que eles não se sentem encorajados a formular aos profissionais da equipe de saúde. Acolhê-las, entrar em contato com suas as vivências se torna imprescindível e isso demanda, além de conhecimentos pedagógicos, outros conhecimentos por parte dos professores.

Pôde-se perceber que contexto do hospital se sobrepõe ao contexto escolar introduzindo nesse último, conteúdos habitualmente não trabalhados na escola. As situações cotidianas de experimentação da dor e das incertezas sobre o amanhã, a continuidade da vida, são temas que necessitam ser constantemente abordados direta ou indiretamente, pois estão inseridos no dia a dia. Fonseca, referindo-se ao profissional que atua nas classes hospitalares, diz:

[...] não Ihe deve faltar noções sobre técnicas e terapêuticas que fazem parte da rotina da enfermaria, sobre as doenças que acometem seus alunos e os problemas (até mesmos emocionais) delas decorrentes para as crianças, e também para os familiares e para as perspectivas de vida fora do hospital (Fonseca, 2003, p.25).

No dizer das professoras, lidar com essas questões, onde a vida e morte são, constantemente, postas em questão, torna-se difícil, pois eles nem sempre se sentem preparados para enfrentá-las:

Para mim a maior dificuldade é lidar com o adolescente que tem consciência do que está acontecendo com ele e te questiona o tempo todo. (Professoras)

O professor, nesse contexto, pode ser um semeador de esperança, reforçando que existe a possibilidade da continuidade da vida fora do hospital. Concordamos com Rocha e Passeggi (2010) quando afirmam que mediar as relações aprendizagens no hospital requer do professor um exercício constante da alegria, da capacidade de sorrir, de se abrir afetivamente e de se dispor a ouvir sensivelmente vozes e silêncios. Para isso, as participantes da pesquisa dizem sentir necessidade de incluir o futuro no trato com as crianças como se pode ver a seguir:

Senta direito, você quer ficar com a coluna torta aos 70 anos! E rapidinho o aluno se recompõem. Assim, damos importância à continuidade e à perspectiva de continuar a vida lá fora. (Professoras)

Apesar de seus alunos estarem doentes, elas afirmam ser importante manter uma rotina de trabalho que leve em conta questões concernentes à educação de crianças. Questões como colocar limites, dizer não, enfim educar se tornam mais complexas:

E colocar limites nesta criança? Ela está doente, mas continua criança, você tem que 
falar não. (...) A professora confia em mim, exige de mim, então eu tenho perspectiva de vida. (Professoras)

No entanto, quando a doença toma uma proporção, na qual não é mais possível a reversão do quadro, as professoras, por meio de seus alunos, são confrontadas com morte que as impacta e afeta.

Tem coisa que choca! Várias vezes eu já me perguntei o que eu estou fazendo aqui? Amanhã não quero voltar mais. Já tive depressão, e quando eu estava grávida..., foi um período que teve muito óbito... E quando eu tinha que ir a UTI e as crianças tinham acabado de tomar rádio. (Professoras)

Morin (1997), salienta que a ideia da morte é uma ideia sem conteúdo, ou melhor, cujo conteúdo é o vazio sem fim. Ela é a mais vazia das ideias vazias, pois seu conteúdo é o impensável, o inexplorável. Por diversas vezes, o trabalho do professor da classe hospitalar é interrompido pelo óbito de algum aluno e falar e refletir sobre isso passa a ser uma necessidade de quem realiza trabalhos pedagógicos no hospital Frente a essa situação, o professor se sente impotente e remetido a lidar, constantemente, com essa questão ontológica que envolve perda, ruptura de vínculos e luto.

As narrativas das professoras enfatizam que é fundamental contar com espaços e tempos dentro do hospital para refletir sobre suas experiências e seus impactos nas dimensões, pessoal e profissional. Nesses espaços, podem pensar e compartilhar modos de lidar com a morte e suas consequências que ronda as classes hospitalares, pois as crianças e adolescentes estão expostos a ela e necessitam, além de enfrentá-la como possibilidade, elaborar seus lutos pelas perdas dos colegas e as emoções que emergem nessas situações e, para isso, necessitam contar com a ajuda das professoras. Rezende (2000) nos ajuda a compreender a importância do cuidado dos profissionais que atuam na área de saúde, devido à complexidade dos sentimentos que transbordam em situações de sobrecarga emocional:

Quando a percepção da proximidade da morte é compartilhada, atenuam-se os sentimentos de solidão e de derrota do destino inexorável, para dar lugar a um momento de cumplicidade, de muita intimidade, com uma estranha leveza no lugar do peso insuportável. Os poetas nos ensinam que a pior morte é a súbita, porque se perde a oportunidade de aprender lições do abismo, lições de sabedoria que só podem ser saboreadas no fim. (Rezende, 2000 p. 80)

As professoras sentem que não têm como não se aproximar dessa realidade, mas para que possam viver suas próprias vidas, precisam também aprender a se afastar.

Fazendo uma reflexão, todas nós temos quer ter momento de lazer e de espiritualidade, 
para garantir o equilíbrio emocional, que muito necessário quando se trabalha dentro de um hospital. Isso faz parte da preservação da saúde do professor e para garantir a busca da saúde do paciente. (Professoras)

É importante destacar que, além de cuidar de si, seria necessário que os professores fossem cuidados e nessa direção os espaços formativos deveriam integrar o cuidar ao formar introduzindo temas como esse nos cursos de formação.

\section{Estar em formação}

O relato sobre o que mais as impacta introduziu a temática da formação. Todas as participantes da pesquisa consideram de vital importância a formação para atuar nas classes hospitalares, ela aproxima os docentes do trabalho nos hospitais.

Se você não tem essa formação você fica insegura, gera muita ansiedade, o professor se sente não funcional, parece que ele não está conseguindo atingir seu objetivo, por isso a formação e importante. (Professoras)

A hospitalização cria um contexto educacional muito específico. Crianças e jovens passam a morar no hospital, um espaço desconhecido tanto para eles como para quem os acompanha, uma nova rotina se impõe permeada por medicamentos, exames, mudança de alimentação, cirurgias e tudo mais que a doença traz consigo.

O grupo de alunos não é constante, sendo composto por alunos, com diferentes ritmos e interesses, o que impede a linearidade dos processos de ensino e aprendizagem. Atuar nesse cenário, requer flexibilidade, dinamismo e capacidade de se inserir na rotina hospitalar e se relacionar com os diferentes membros da equipe multidisciplinar que presta atendimento aos pacientes.

Para aqueles que não tiveram formação anterior, esse processo torna-se muito mais difícil, quase impossível de ser vivido, provocando desistência em muitos que são pegos de surpresa pela realidade do hospital. Barros (2007) afirma que a falta de uma formação específica sobre os quadros de adoecimento das crianças que prepare os professores para o ingresso no ambiente hospitalar é um fator preponderante para a permanência e para o desempenho satisfatório dos professores. A formação, também, exerce a função de validar a atuação das professoras frente aos outros profissionais que atuam no hospital: 
Como você vai se superar se você não buscar formação? Para você estar minimamente confortável, você tem que mostrar a equipe médica, por exemplo, que na minha área eu sei desempenhar bem o meu trabalho. (Professoras)

Os docentes que atuam nos hospitais, comumente, participam de equipes multidisciplinares e para que possam colaborar de maneira adequada e, dessa forma, serem respeitados por seus colegas de trabalho, a formação se torna imprescindível, pois ela possibilita a aquisição de conhecimentos que podem, além de contribuir com o exercício da docência, colaborar para com o trabalho da equipe multidisciplinar.

Para Fonseca (2003), o professor é um veículo importante de informações, uma vez que, no ambiente da classe hospitalar, as crianças têm atitudes mais espontâneas, em relação às suas vivências no hospital, o que pode contribuir muito para uma intervenção da equipe junto à criança hospitalizada. Ao professor, cabe ajudar a equipe com informações e percepções a respeito da criança a fim de contribuir para uma melhor assistência de sua saúde. Essa integração de ações entre os diferentes profissionais configura-se como um fator importante no processo de internamento e de busca de melhoria na condição da saúde e do bem-estar.

No entanto, na perspectiva das professoras, só a formação que antecede a atuação não é suficiente. A narrativa das professoras mostra que a formação continuada, também, cumpre um papel fundamental, pois se o exercício da docência nas escolas regulares provoca questões e dúvidas, nas classes hospitalares, elas surgem com muito mais frequência, o que demanda dos professores novos estudos e reflexões.

A formação em serviço é indispensável, é necessária, isso para qualquer área, em nossa área ainda é difícil porque a área está em formação. (Professoras)

Refletindo sobre a formação, as professoras salientaram que essa não se reduz a participação em cursos, ela ocorre de diferentes maneiras. Salientam a importância da reflexão uma maneira de articular a experiência aos conhecimentos teóricos.

\section{A prática revisitada}

A capacidade de perceber a complexidade da situação vivenciada, a funcionalidade pedagógica no espaço hospitalar, ancora-se na reflexão. O professor depara-se com situações singulares tendo que construir novos trajetos pedagógicos para atender aos objetivos propostos.

Entender as particularidades da classe hospitalar, alunos heterogêneos, cada aluno é considerado em sua condição. A criança está doente, o professor tem que ter um lado humano muito aflorado, pois a criança está debilitada, agora o mais difícil num hospital 
é você ter claro que você não sabe tudo, e a criança que está doente te gera muitas dúvidas, será que eu devo continuar? Parece que ela não está respirando, será que eu faço o que eu posso? Você tem que gostar muito mais do que da classe regular, pois a criança da classe regular não está doente. Uma hora você é a professora, outra hora você é auxiliar de classe, outra você só é amiga, eu sou o que for o mais confortável para a criança. (Professoras)

Levando em conta que cada aluno é único e que a doença se singulariza em cada um, é necessário que pedagogo hospitalar desenvolva um olhar diferenciado e uma escuta sensível capaz de acolher e lidar com as especificidades e o momento de cada aluno e isso só se torna possível com o apoio da formação. A história de vida das crianças e dos adolescentes internados, sua cultura, seus interesses também são aspectos fundamentais que o professor precisa conhecer para desenvolver estratégias de aprendizagem diversificadas. Como afirmam Matos e Mugiatti, (2009, p. 101):

A assistência pedagógica, na hospitalização, sugere uma ação educativa que se adapta às manifestações de cada criança/adolescentes, em diferentes circunstancias, nos enfoques didáticos, metodológicos, lúdicos e pessoais. Neste sentido, ela apresenta, em todos os momentos, um alto grau de flexibilidade e adaptabilidade às estruturas.

O modo como as atividades se organizam é determinante para que os alunos construam aprendizagens significativas. Neste sentido, um dos desafios enfrentadas no exercício da docência no contexto hospitalar refere-se à concepção, função e adaptação do currículo o que requer rever objetivos, conteúdos, atividades e avaliação.

Você está atendendo, a mãe ao seu lado, o médico ali, aí vem a enfermeira e te interrompe, você tem que saber ser interrompida, por mais que seu trabalho seja importante, a criança está ali para se tratar, então você tem que finalizar a atividade de uma forma que deixe a criança tranquila. É necessário saber lidar com sua frustração, porque você planejou uma aula e não deu conta. (Professoras)

Diante de inúmeros acontecimentos que se distanciam das experiências anteriores do professor, ele necessita recriar suas práticas constantemente. $O$ atendimento feito pelo professor da Classe Hospitalar não está restrito ao ambiente de uma sala de aula. Constantemente o professor depara-se com situações onde a criança necessita de atendimento no leito ou na UTI. Esse atendimento faz parte da rotina da Classe Hospitalar e obriga o professor a reorganizar-se, em termos de recursos, para torná-lo viável. A rotina pedagógica ganha outros contornos nas classes hospitalares.

A situação de cada dia contar com novos alunos e surpresa de, talvez, no dia seguinte não os encontrar mais. Ás vezes, alguns muito dispostos, outros quase sem disposição, mas mesmo assim, com vontade de fazer as atividades propostas. Tem que ter muito equilíbrio, para dar conta de um dia de trabalho assim. (Professoras) 
Aqui você tem que ser rápida... Um está aqui na frente, outro está na sua perna e o outro vomitou... E aí o que você faz? Como você faz? (...) É heroico aqui, ou a gente enlouquece para sempre, ou, ao passar por aqui, se torna alguém muito melhor. (Professoras)

Consideram importante observar suas práticas: como ela se dá; quais atividades interessam mais aos alunos; onde eles preferem ou podem ficar; o que os alegra; o que os tranquiliza e o que os agita, para poder organizar suas atividades. Contar com a ajuda de colegas que vivem experiências semelhantes, torna-se fundamental para que as reflexões individuais possam ser potencializadas. Nesse sentido, procuram criar, em seu próprio local de atuação, espaços para troca e discussão com seus pares.

Destacam também a importância da formação que ocorre nos grupos multidisciplinares, pois a troca, com profissionais de outras áreas, possibilita olhar para as experiências vividas por novos ângulos, o que enriquece o repertório de todos. Essa inter-relação do professor com os diferentes profissionais que atuam no hospital é bastante significativa, pois permite troca de informações sobre o aluno/paciente, sobre a doença a qual ele está acometido, sobre suas limitações, favorecendo uma percepção mais clara e objetiva das possibilidades de atuação do professor.

\section{Considerações possíveis}

O artigo se iniciou com o intuito de colocar em evidência temas relevantes abordados pelos participantes de uma pesquisa realizada com professores que atuam em classes hospitalares de uma escola, localizada em um hospital de São Paulo que atende pacientes com tumores malignos.

Com base na análise da narrativa, fruto do diálogo entre as professoras, foi possível perceber que elas, inicialmente, sentiram necessidade de falar de seus alunos. A situação de adoecimento em que se encontram faz com que tenham necessidades educativas específicas. Muitas vezes é requerido deles repouso parcial ou absoluto, a utilização de equipamentos de suporte à vida, a ingestão controlada de medicamentos e a imobilização parcial ou total.

Sobrepondo-se a isso, a doença, também, afasta as crianças e adolescentes da convivência social e familiar o que os deixa ainda mais fragilizados.

Só após falar deles, de suas necessidades pedagógicas puderam abordar a formação do professor que atua em classes hospitalares. Eles ressaltaram a importância de uma formação anterior específica, no entanto, só essa formação não é suficiente, é necessário estar em processo de formação contínua. Para elas a formação continuada assume diferentes facetas, tanto pode acontecer por meio de cursos, como também em grupos reflexivos compostos por pares, ou por membros da equipe multidisciplinar 
que atua no hospital. Destacaram, também, a importância da reflexão que, por exercer a mediação entre a prática e a teoria, deve permear todos os processos de formação.

As crianças e os jovens, postos em situação de vulnerabilidade pela doença e seus desdobramentos, requerem uma atenção e um cuidado especiais, pois em tenra idade, estão sendo confrontados por questões de difícil elaboração, até mesmo para os adultos.

A oportunidade de poder abordar essas questões, em meio a aprendizagem de outros conteúdos que os ligam a vida e ao futuro, é de grande valia para que possam incluir suas experiências, de um modo menos traumático, em suas trajetórias de vida. Para isso, necessitam contar com professores que, além de garantir a continuidade de seu processo de escolar, possam exercer seu trabalho em uma dimensão mais ampla que diz respeito ao acolhimento e a escuta sensível daqueles que, prematuramente têm que enfrentar além dos desafios relacionados a vida, os que dizem respeito à saúde, debilitada pela doença e suas consequências dolorosas.

Finalizando o que se pode dizer é que não se dispõem de modelos prontos para serem oferecidos, mas sim modos de atuação a serem compartilhados que se singularizam frente a cada criança e jovem que participa das classes hospitalares.

\section{Referências}

BARROS. A. S. (2007) Contribuições da Educação Profissional em Saúde à Formação para o Trabalho em Classes Hospitalares. Caderno CEDES. Campinas, vol. 27, n. 73, p. 249-368.

Bolívar, A. (2002). “¿De nobis ipsis silemus?”: Epistemología de la investigación biográfico-narrativa en educación. Revista Electrónica de Investigación Educativa, 4 (1), 41-65.

Delory-Momberger, C. (2016) A pesquisa biográfica ou a construção compartilhada de um saber do singular. Revista Brasileira de Pesquisa (Auto)Biográfica, 01, (01), 133-147.

Delory-Momberger, C. (2016) A experiência da doença: um tocar do existir. Educação e Contemporaneidade 25, (46), 25-31.

Fontes, R. (2005). A escuta pedagógica à criança hospitalizada: discutindo o papel da educação no hospital. Revista Brasileira de Educação. Rio de Janeiro, (29), 119138. 
Fonseca, E.S. (2003) Atendimento escolar no ambiente hospitalar. São Paulo: Menon. Gatti, B. A (2005) Grupo focal na pesquisa em ciências sociais e humanas. Brasília: Líber Livro.

Matos, E.L.M. \& MUGIATTI, M.M.T. (2009). Pedagogia hospitalar. Curitiba: Champagnat.

Mazer, S. M. \& Tinós, L.M.S. (2003). Classe hospitalar como possibilidade de atuação do pedagogo em educação especial: compreendendo trajetórias profissionais de professoras. Cadernos da Pedagogia, 6 (12), 141-155.

Ministério da Educação. Secretaria de Educação Especial. (2002). Classe hospitalar e atendimento pedagógico domiciliar: estratégias e orientações. Brasília, DF:

MEC/SEESP, Disponível em <http://portal.mec.gov.br/seesp/arquivos/pdf/livro9. pdf. Acesso em 25/08/2016.

Morin, E. (1997). O Homem e a morte. Rio de Janeiro: Imago.

Paula, E. M.A.T. \& Matos, E. (2007) Educação para crianças hospitalizadas: as várias faces da pedagogia no contexto hospitalar. Cadernos Cedes, 27, (73), 251-252.

Passeggi, M. da C. Rocha, S. M. e De Conti, L. (2016) (Con)viver com o adoecimento: narrativas de crianças com doenças crônicas. Revista da FAEEBA - Educação e Contemporaneidade, Salvador, 25, (46), p. 45-57

Rezende, V.L. (2000). Osúltimos momentos - abordagem psicológica para pacientes terminais. In: V.L. Rezende, (Org.) Reflexões sobre a vida e a morte. Campinas (SP): Unicamp.

Rocha, S. M. da; Passeggi, M. da C. (2010) Classe hospitalar: um espaço de vivências educativas para crianças e adolescentes em tratamento de saúde. Revista @ mbienteeducação, São Paulo, 2,(1), p. 113-121.

Schilke, A.L.T. (2008). representações sociais de ser professor em espaço hospitalar. Dissertação de mestrado, Universidade Estácio de Sá, Rio de Janeiro.

Silva, A.P.M. (2010). O Pedagogo como membro da equipe multidisciplinar em hospitais oncológicos. Dissertação de mestrado. Universidade de São Paulo, São Paulo.

Souza, E. C. (2014). Diálogos cruzados sobre pesquisa (auto)biográfica: análise compreensiva-interpretativa e política de sentido. Educação/Santa Maria 39 (01), 39-50. 
Cristiane Nobre Nunes é Graduação em Pedagogia pela Pontifícia Universidade Católica de São Paulo. Mestre em Educação pela UNICID. Professora da Faculdade Sumaré. Membro do Grupo de Pesquisa Narrar - Narrativas, aprendizagem e formação. E-mail: crisnonu@hotmail.com.

Ecleide Cunico Furlanetto é Mestre em Psicologia da Educação pela PUC/SP. Doutora em Educação pela PUC/SP. Professora do PPGE da UNICID. Líder do Grupo de Pesquisa Narrar - Narrativas, aprendizagem e formação, cadastrado no CNPq. E-mail:ecleide@terra.com.br. 